\title{
Risco de estresse térmico para o feijoeiro em Santa Maria, RS
}

\author{
Thermal stress risk for common bean in Santa Maria, RS, Brazil
}

\author{
Joel Cordeiro da SilvaI Arno Bernardo Heldwein ${ }^{\text {II }}$ Fabrina Bolzan Martins ${ }^{\text {II }}$ \\ Nereu Augusto Streck ${ }^{\text {II }}$ Fabrício Ivan Guse ${ }^{\text {II }}$
}

\section{RESUMO}

A quantificação da disponibilidade térmica para os cultivos é importante no planejamento das atividades do agronegócio. O objetivo deste trabalho foi determinar as datas de semeadura com menor risco de ocorrência de altas temperaturas do ar, durante a floração do feijoeiro, e verificar se existe diferença entre grupos de hábito de crescimento de feijoeiro quanto à freqüência de ocorrência de temperaturas elevadas, para a região central do Rio Grande do Sul. Para tanto, foi determinada a freqüência de ocorrência de temperatura máxima diária do ar maior ou igual a 28, 30 e $32^{\circ} \mathrm{C}$, durante o período mais crítico de sensibilidade do feijoeiro às altas temperaturas, que ocorre do aparecimento dos botões florais ao aparecimento dos primeiros legumes cheios, para três grupos de hábitos de crescimento de feijoeiro e dois períodos recomendados de semeadura (cultivo de safra e safrinha). Dentro de cada período recomendado, foram consideradas semeaduras a cada cinco dias, de 15 de agosto a 15 de novembro, para o cultivo de safra, e de 10 de janeiro até o final de fevereiro, para o cultivo de safrinha. $O$ ciclo de cultivo foi simulado para cada ano dos dados da estação climatológica principal de Santa Maria, no período de 01 agosto de 1968 até 31 de julho de 2004. Não houve diferença significativa entre os grupos de hábito de crescimento para a probabilidade de ocorrência de temperaturas elevadas. Há menor risco de danos causados por altas temperaturas do ar quando a semeadura é realizada no início do período recomendado para o cultivo da safra e no final do período recomendado para o cultivo da safrinha.

Palavras-chave: épocas de semeadura, temperatura do ar, Phaseolus vulgaris $L$.

\section{ABSTRACT}

Quantifying thermal conditions for crops is important for planning agribusiness activities. The purpose of this study was to determine sowing dates with smaller risk of high air temperatures during flowering of common bean and to verify if there are differences among maturation groups considering the occurrence frequency of elevated temperatures, in the Central Region of Rio Grande do Sul State. The occurrence frequency of daily maximum air temperatures greater than or equal to 28, 30 and $32^{\circ} \mathrm{C}$ was determined for the period from bud emission to beginning of grain formation for three maturation groups and for each sowing date. The crop cycle was simulated with data collected in a climatological station at Santa Maria, from August 1968 to July 2004. There was not significant difference among the maturation groups for frequency of occurrence of elevated temperatures. There is lower risk of damages caused by elevated air temperatures when sowing is performed early in the spring growing season and late in the autumn growing season.

Key words: sowing season, air temperature, Phaseolus vulgaris $L$.

\section{INTRODUÇÃO}

O conhecimento da disponibilidade térmica de um local e para uma determinada cultura é importante para definir as épocas de semeadura em que há menor risco à produção, escolher as cultivares mais adequadas e adotar práticas de manejo de modificação do ambiente de cultivo.

Apesar do cultivo do feijoeiro ser amplamente difundido geograficamente, a sua produtividade é afetada pela temperatura do ar. Conforme EMBRAPA (2003), a temperatura do ar é um dos elementos climáticos de maior importância para o crescimento e desenvolvimento do feijoeiro. A faixa de

IPrograma de Pós-graduação em Engenharia Agrícola, Departamento de Fitotecnia, Centro de Ciências Rurais (CCR), Universidade Federal de Santa Maria (UFSM), 97105-900, Santa Maria, RS, Brasil. E-mail: joelcordeiro@mail.ufsm.br. Autor para correspondência. IIDepartamento de Fitotecnia, CCR, UFSM. Santa Maria, RS. Brasil. 
temperatura do ar ideal para o cultivo do feijoeiro está próxima de $29^{\circ} \mathrm{C}$, durante o dia, e de $21^{\circ} \mathrm{C}$ durante a noite (EMBRAPA, 2003). Conforme MALUF et al. (2001), a temperatura média do ciclo ideal para o feijoeiro situa-se entre 20 e $22^{\circ} \mathrm{C}$, sendo a temperatura ótima igual a $21^{\circ} \mathrm{C}$ e a temperatura máxima média do ciclo não pode ser superior a $24^{\circ} \mathrm{C}$. Valores de temperatura máxima do ar entre 30 e $40^{\circ} \mathrm{C}$ causam danos às plantas de feijão, (GONÇALVES et al., 1997; CARAMORI et al., 2001). Já em EMBRAPA (2003), o limite de $35^{\circ} \mathrm{C}$ é considerado crítico, acima do qual há danos causados por temperaturas elevadas.

O momento fisiológico em que há maior sensibilidade do feijoeiro em relação às temperaturas elevadas é o subperíodo reprodutivo, desde a emissão dos botões florais até o início da formação das vagens. Os principais danos causados por temperaturas do ar elevadas são: abortamento de flores e vagens, redução do número de grãos por vagem, crescimento vegetativo exagerado e grãos com menor massa seca, os quais afetam diretamente a produtividade (EMBRAPA, 2003). Esses danos por estresse térmico são causados pela elevada produção de etileno na planta (SAUTER \& GEPTS, 1990) e pela esterilização do grão de pólen (WEAVER \& TIMM, 1985).

No zoneamento de riscos climáticos e na definição de datas de semeadura para o feijão no Paraná, CARAMORI et al. (2001) utilizaram a freqüência relativa de ocorrência de temperatura máxima do ar acima de $32^{\circ} \mathrm{C}$. Porém, GONÇALVES et al. (1997) haviam utilizado a temperatura de $30^{\circ} \mathrm{C}$ para quantificar a probabilidade de ocorrência de estresse térmico. Estes resultados indicam que não há consenso entre os pesquisadores do valor exato de temperatura que causa danos ao feijoeiro, pois, além do efeito direto da temperatura, ocorrem interações com outras variáveis, como a deficiência hídrica (CARGNELUTTI FILHO et al., 2005). Certamente os danos causados por temperaturas do ar elevadas são tanto maiores quanto maior for o aquecimento do ar e das plantas e quanto mais tempo as plantas permanecerem em condições de estresse.

O objetivo deste trabalho foi determinar as épocas de semeadura com menor risco de ocorrência de temperatura do ar elevadas, durante a floração do feijoeiro, e verificar se existe diferença entre os grupos de hábitos de crescimento de feijoeiro quanto à freqüência de ocorrência de temperaturas elevadas, para a região ecoclimática de Santa Maria, RS.

\section{MATERIAL E MÉTODOS}

Foram utilizados dados meteorológicos diários de temperatura máxima do ar coletados a 1,5m de altura no interior do abrigo meteorológico da Estação Climatológica Principal de Santa Maria, localizada no Departamento de Fitotecnia da Universidade Federal de Santa Maria (latitude: $29^{\circ} 43^{\prime} 23$ ”S, longitude: $53^{\circ}$ 43' 15”W e altitude: $95 \mathrm{~m}$ ), durante o período de 01 de agosto de 1968 a 31 de julho de 2004.

O período adotado como de maior risco de prejuízo às altas temperaturas para o feijoeiro foi o período compreendido entre o aparecimento dos botões florais e o aparecimento das primeiras vagens cheias. O momento da ocorrência destes dois estágios de desenvolvimento e a duração deste período de risco foram definidos considerando-se várias datas de semeadura e grupos de hábitos de crescimento. Os períodos de semeadura utilizados foram semelhantes aos indicados como períodos favoráveis de semeadura para o feijão por MALUF et al. (2001), que vai de 11 de agosto a 10 de novembro, para o cultivo de safra, e de 11 de janeiro a 28 de fevereiro para a safrinha. Neste trabalho, foram considerados como datas de semeadura o primeiro, o quinto, o décimo, o décimo quinto, o vigésimo e o vigésimo quinto dia de cada mês, no período compreendido entre 15 de agosto e 15 de novembro, para o cultivo de safra, e 10 de janeiro e final de fevereiro, para o cultivo de safrinha.

Foram considerados três grupos de hábitos de crescimento de feijoeiro: tipo I, tipo II e tipo III (DOURADO NETO \& FANCELLI, 2000), os quais abrangem a maioria dos genótipos cultivados no Brasil. O tipo I apresenta plantas com crescimento determinado, de altura entre 25 e $50 \mathrm{~cm}$, eretas, com haste principal e ramos laterais terminando em inflorescências e de ciclo curto (85 dias em média). O tipo II apresenta plantas de crescimento indeterminado, crescimento pouco inclinado e com ramificações nãonumerosas e curtas, aspecto arbustivo e ciclo com duração média de 90 dias. O tipo III apresenta plantas de hábito de crescimento indeterminado e prostrado ou semiprostrado, com numerosas ramificações, com aptidão trepadora e duração média do ciclo de 105 dias.

$\mathrm{O}$ período compreendido entre o aparecimento dos botões florais e o aparecimento das primeiras vagens cheias para o tipo I inicia aos 23 dias após a emergência (DAE) e termina aos $44 \mathrm{DAE}$; para o tipo II está compreendido entre 27 e 50 DAE, e para o tipo III, entre 30 e 53 DAE (DOURADO NETO \& FANCELLI, 2000). O desconhecimento ou a inexistência de modelos de simulação para a duração do ciclo, considerando-se várias cultivares, bem como a existência de evidências de que a duração do ciclo do feijoeiro e de suas etapas podem ser influenciadas por 
diversos fatores, notadamente a condição hídrica do solo, o fotoperíodo, além da temperatura do ar (KORNEGAY et al., 1993; WHITE et al., 1996; GU et al., 1998; WALLACE \& YAN, 1998), conduziram à adoção dos valores acima citados e sete dias para a safra e oito dias para a safrinha, para a duração do subperíodo semeadura - emergência, baseando-se em médias de observações locais (RIBEIRO et al., 2006).

Para determinação da freqüência de ocorrência de temperaturas do ar elevadas durante o período crítico dos diferentes grupos de hábitos de crescimento em cada data de semeadura, foram utilizados os dados diários de temperatura máxima do ar, contabilizando-se o número de dias com temperatura máxima maior ou igual a $28^{\circ} \mathrm{C}, 30^{\circ} \mathrm{C}$ e $32^{\circ} \mathrm{C}$ que ocorreram durante o período crítico para os três grupos de hábitos de crescimento, em relação ao número total de dias do período crítico, para todos os anos do banco de dados e para cada data de semeadura. Equações de regressão foram estimadas para relacionar a probabilidade de ocorrência de determinado valor de temperatura com as diferentes épocas de semeadura simuladas durante o período recomendado para a safra e safrinha, para cada grupo de hábito de crescimento.

Os valores da freqüência de ocorrência de temperatura máxima, maiores ou iguais a 28,30 e $32^{\circ} \mathrm{C}$, para cada grupo de hábito de crescimento, foram comparados pelo teste t.

\section{RESULTADOS E DISCUSSÃO}

A análise de comparação das freqüências de temperaturas máximas entre os grupos de hábitos de crescimento, pelo teste t, demonstrou que não houve diferença significativa entre os grupos de hábitos de crescimento, considerando-se os três níveis de freqüência de ocorrência de temperatura máxima durante o período crítico.

Analisando-se a variação da freqüência de ocorrência de temperatura máxima do ar durante a floração, para as diferentes épocas de semeadura simuladas, verifica-se que esta é crescente ao longo do período recomendado para a semeadura do cultivo da safra e decrescente ao longo do período recomendado para a semeadura do cultivo da safrinha, para todos os níveis de temperatura analisados. De uma maneira geral, considerando-se todos os anos e todos os hábitos de crescimento, a freqüência observada para a ocorrência de temperaturas máximas do ar elevadas (Figura 1) foi de aproximadamente $77 \%$, $55 \%$ e $33 \%$ dos dias, para 28,30 e $32^{\circ} \mathrm{C}$, respectivamente, quando a semeadura foi realizada no final da safra (15 de novembro), enquanto que, para o início da safrinha (10 de janeiro), as freqüências de ocorrência de valores iguais ou superiores a $28^{\circ} \mathrm{C}, 30^{\circ} \mathrm{C}$ e $32^{\circ} \mathrm{C}$, foram de aproximadamente $70 \%$, $47 \%$ e $24 \%$, respectivamente (Figura 1).

Estes resultados indicam que, para o valor de temperatura máxima diária do ar de $30^{\circ} \mathrm{C}$, em mais da metade dos anos, há probabilidade de redução no rendimento, causado por estresse térmico, quando a semeadura for realizada próxima do final do período recomendado para o cultivo da safra (15 de novembro) e, em praticamente metade dos anos, quando a semeadura for realizada no início do período recomendado para a safrinha (10 de janeiro), enquanto que a probabilidade de ocorrência de temperaturas iguais ou acima de $30^{\circ} \mathrm{C}$ é de apenas aproximadamente $7 \%$ quando a semeadura é realizada no início do período recomendado para a safra e menor do que $15 \%$ quando a semeadura é realizada próxima do final do período recomendado para a safrinha. Isto ocorre porque, à medida que a data de semeadura é mais próxima do solstício de verão, maior é a disponibilidade de radiação e maiores são os valores de temperatura do ar. Portanto, o risco de dano causado por temperaturas elevadas é maior quando a semeadura for realizada próxima da data de 15 de novembro, para a safra. Na safrinha, o risco é maior quando a semeadura é realizada no seu início, próximo da data de 10 de janeiro. Em virtude disso, para minimizar o risco de dano causado por temperatura elevada do ar durante a floração, recomendam-se as épocas do início da safra e do final da safrinha.

A tendência de aumento do risco de ocorrência de estresse causado por temperaturas do ar elevadas também foi observada por GONÇALVEZ et al. (1997) e por CARAMORI et al. (2001), para algumas localidades do sul do Paraná. Para Santa Maria, essa tendência também foi constatada por ESTEFANEL et al. (1994) e por CARGNELUTTI FILHO et al. (2005), usando dados decendiais.

Na tabela 1, estão as equações de regressão, estimadas a partir dos dados apresentados na figura 1, que relacionam a data de semeadura com a probabilidade de ocorrência de temperaturas máximas do ar prejudiciais. Utilizando-se essas equações é possível calcular a probabilidade $(\mathrm{F})$, ou o risco assumido, de haver estresse térmico quando a semeadura for realizada em determinada data. As equações foram estimadas utilizando-se o dia Juliano do ano, dia 1 para o dia primeiro de janeiro até dia 365 para dia 31 de dezembro, paras as datas de semeadura. Assim, para calcular-se o valor de F, é necessário converter a data de semeadura para o dia do ano. 

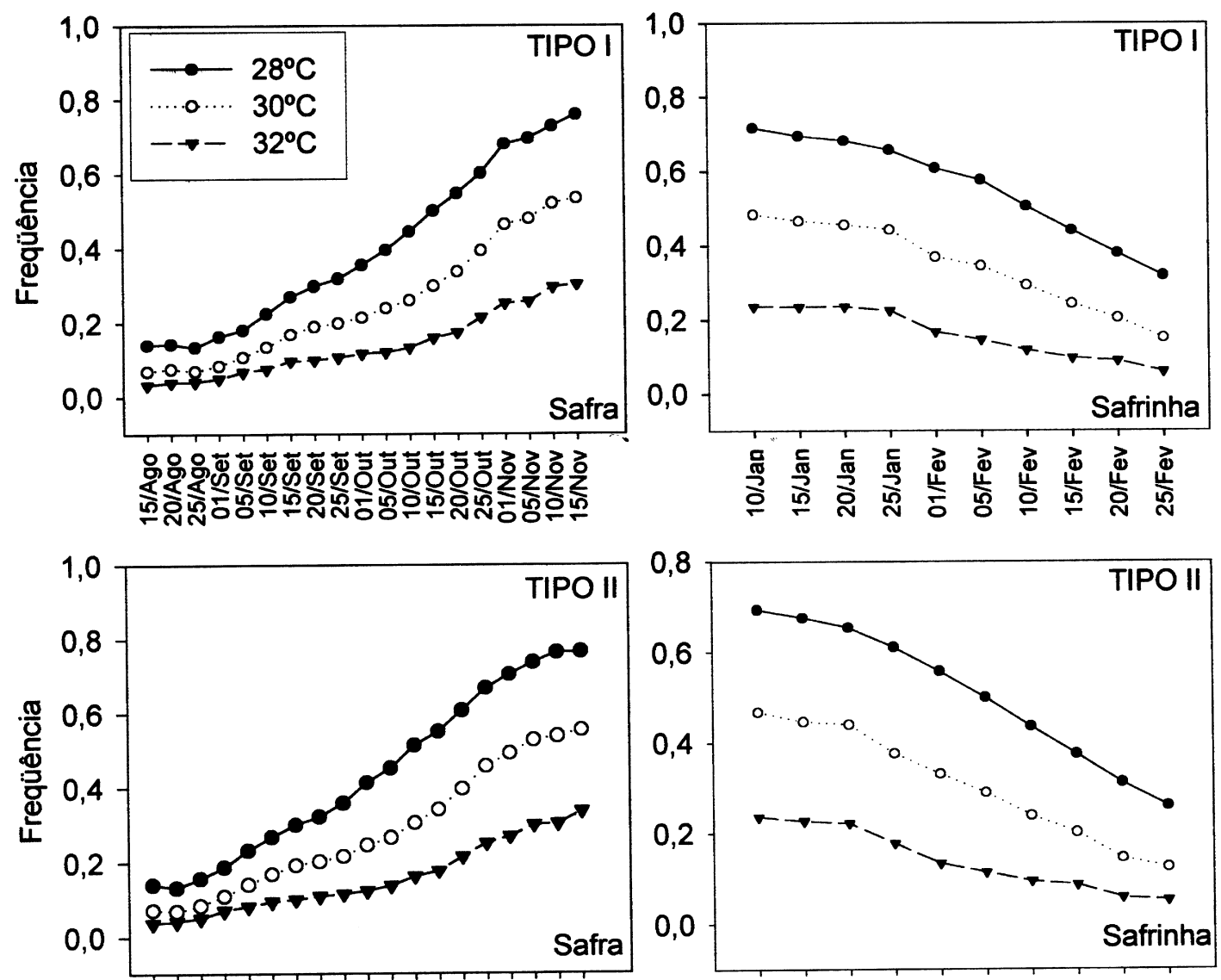

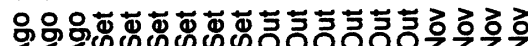
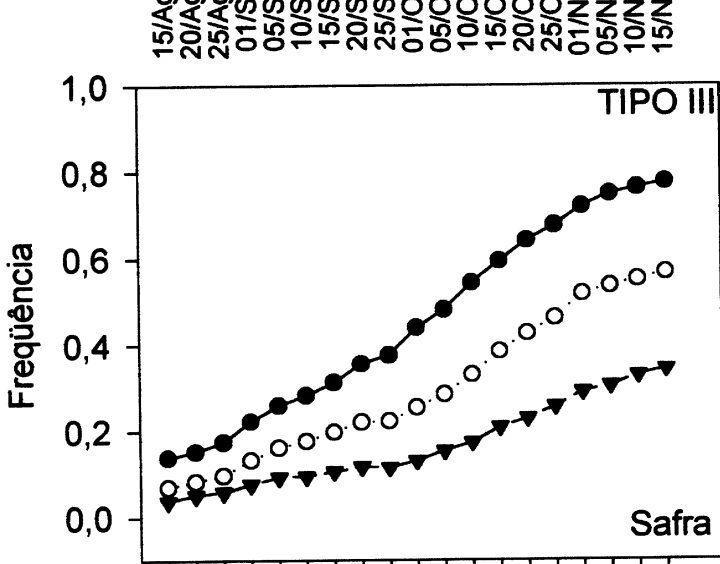

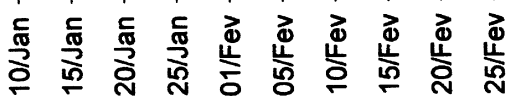

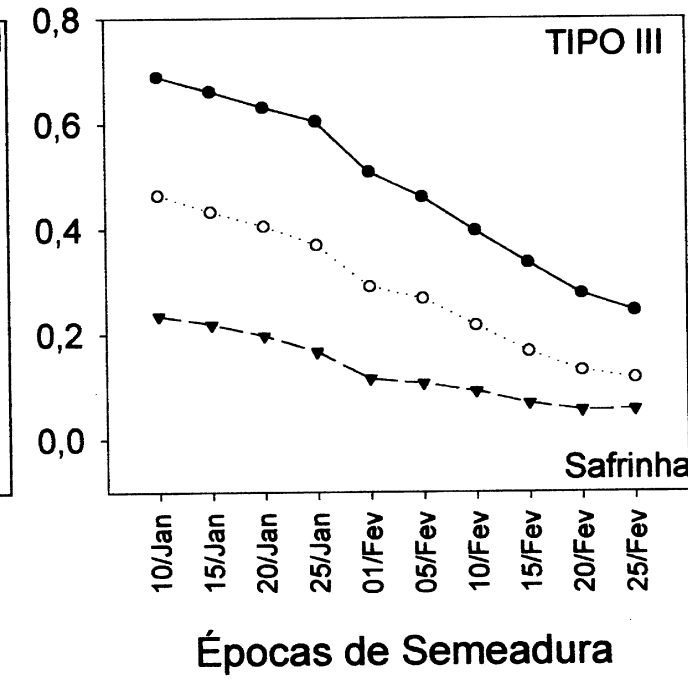

Figura 1 - Freqüência de ocorrência de temperatura máxima do ar maior ou igual a $28^{\circ} \mathrm{C}, 30^{\circ} \mathrm{C}$ e $32^{\circ} \mathrm{C}$, durante o período crítico (aparecimento dos botões florais - aparecimento das primeiras vagens) para os três grupos (tipos I, II e III) de hábito de crescimento do feijoeiro, em função das datas de semeadura dentro do período recomendado para o cultivo de safra e safrinha. Santa Maria - RS. 
Tabela 1 - Equações e coeficientes de determinação $\left(R_{a j}^{2}\right)$ ajustados para determinar a probabilidade de ocorrência (F) de temperaturas máximas (T) do ar, prejudiciais, para cada estação de cultivo e para cada grupo de hábito de crescimento (tipos), em função do dia Juliano do ano (DA) em que foram simuladas as semeaduras. Santa Maria, RS.

\begin{tabular}{|c|c|c|c|}
\hline & $\mathrm{T}$ & Equação & $\mathrm{R}_{\mathrm{aj}}^{2}$ \\
\hline \multirow{4}{*}{ Tipo I } & & -- Safra (15/agosto até 15/novembro) --- & \\
\hline & 28 & $F^{0,5}=-1,07387+0,006158 D A$ & 0,9908 \\
\hline & 30 & $F^{0,5}=-1,0868574+0,00573 D A$ & 0,9886 \\
\hline & 32 & $F^{0,5}=-0,8241+0,00431 D A$ & 0,9794 \\
\hline \multirow{3}{*}{ Tipo II } & 28 & $F^{0,5}=-1,00347+0,00601 D A$ & 0,9852 \\
\hline & 30 & $F^{0,5}=-1,0374+0,00506 D A$ & 0,9879 \\
\hline & 32 & $F^{0,5}=-0,8181+0,00437 D A$ & 0,9826 \\
\hline \multirow{4}{*}{ Tipo III } & 28 & $F^{0,5}=-0,92695+0,0058 D A$ & 0,9805 \\
\hline & 30 & $F^{0,5}=-0,99435+0,00556 D A$ & 0,9871 \\
\hline & 32 & $F^{0,5}=-0,81222+0,0044 D A$ & 0,9866 \\
\hline & & ---- Safrinha (10/Janeiro até 25/Fevereirc & \\
\hline \multirow{3}{*}{ Tipo I } & 28 & $F=0,7355-0,00013 D A^{2}$ & 0,9950 \\
\hline & 30 & $F=0,4955-0,00011 D A^{2}$ & 0,9906 \\
\hline & 32 & $F=0,2451-0,00006 D A^{2}$ & 0,9392 \\
\hline \multirow{3}{*}{ Tipo II } & 28 & $F=0,7045-0,00015 D A^{2}$ & 0,9920 \\
\hline & 30 & $F=0,4634-0,00012 D A^{2}$ & 0,9681 \\
\hline & 32 & $F=0,2259-0,00006 D A^{2}$ & 0,8894 \\
\hline \multirow{3}{*}{ Tipo III } & 28 & $F=0,68597-0,00016 D A^{2}$ & 0,9735 \\
\hline & 30 & $F=0,55784-0,00819 D A^{2}$ & 0,9893 \\
\hline & 32 & $F=0,27399-0,00432 D A^{2}$ & 0,9567 \\
\hline
\end{tabular}

\section{CONCLUSÃO}

Existe maior probabilidade de danos ao feijoeiro causados por temperatura do ar elevada quando a semeadura é realizada no final do período recomendado para a safra e no início do período recomendado para a safrinha. Não existe diferença significativa entre os grupos de hábitos de crescimento de feijoeiro quanto à freqüência de ocorrência de temperatura máxima do ar prejudicial durante o subperíodo que ocorre entre o aparecimento dos botões florais ao aparecimento dos primeiros legumes cheios.

\section{REFERÊNCIAS}

CARAMORI, P.H. et al. Zoneamento de riscos climáticos e definição de datas de semeadura para o feijão no Paraná. Revista
Brasileira de Agrometeorologia, Passo Fundo, v.9, n.3, (n Especial: Zoneamento Agrícola), p.477-485, 2001.

CARGNELUTTI FILHO, A. et al. Temperaturas máximas prejudiciais ao feijoeiro no Estado do Rio Grande do Sul, Brasil. Ciência Rural, Santa Maria, v.35, n.5, p.1019-1026, 2005.

DOURADO NETO, D.; FANCELLI, A.L. Produção de feijão. Guaíba: Agropecuária, 2000. 385p.

EMBRAPA. Feijão: o produtor pergunta, a Embrapa responde. Brasília: Embrapa Informação Tecnológica, 2003. 203p.

ESTEFANEL, V. et al. Probabilidade de ocorrência de temperaturas máximas do ar prejudiciais aos cultivos agrícolas em Santa Maria, RS. Revista Brasileira de Agrometeorologia, Santa Maria, v.2, p.57-63, 1994. 
GONÇALVES, S.L. et al. Probabilidade de ocorrência de temperaturas superiores a $30^{\circ} \mathrm{C}$ no florescimento do feijoeiro (Phaseolus vulgaris L), cultivado na safra das águas no estado do Paraná. Revista Brasileira de Agrometeorologia, Santa Maria, v.5, n.1, p.99-107, 1997.

GU, W. et al. Analysis of genes controlling photoperiod sensitivity in common bean usind DNA markers. Euphytica, Netherlands, v.102, n.1, p.125-132, 1998.

KORNEGAY, J. et al. Inheritance of photoperiod response in Andean and Mesoamerican common bean. Crop Science, v.33, p.977-984, 1993.

MALUF, J.R.T. et al. Zoneamento de riscos climáticos para a cultura de feijão no Rio Grande do Sul. Revista Brasileira de Agrometeorologia, Passo Fundo, v.9, n.3 ( $\mathrm{n}^{\circ}$ Especial: Zoneamento Agrícola), p.468-476, 2001.

RIBEIRO, N.D. et al. Variabilidade genética em feijão para tolerância a alta temperatura do ar no período reprodutivo. In:
REUNIÃO SUL BRASILEIRA DE FEIJÃO, 8., 2006, Londrina. Anais... Londrina, IAPAR, 2006. p.84-86.

SAUTER, K.J.; GEPTS, P. Leaf ethylene evolution level following high temperature stress in common bean. Horticulture Science, Alexandria, v.25, n.10, p.1282-1284, 1990 .

WEAVER, M.L.; TIMM, H. Influence of temperature and plant water status on pollen viability in beans. Journal of the American Society for Horticultural Science, Alexandria, v.110, n.6, p.797-799, 1985.

WALLACE, D.H.; YAN, W.K. Whole system plant physiology-breeding for plant maturity, adaptation, and yeld. Wallingford, Oxon, UK: CAB International, 1998. 462p.

WHITE, J.W. et al. Inheriterance of temperature sensivity of the photoperiod response in common bean (Phaseolus vulgaris L.). Euphytica. v.91, n.1, p.5-8, 1996. 